\title{
Chronic temperature stress inhibits reproduction and disrupts endocytosis via chaperone titration in Caenorhabditis elegans
}

Rosemary N. Plagens, Isiah Mossiah, Karen S. Kim Guisbert and Eric Guisbert* (1)

\begin{abstract}
Background: Temperature influences biology at all levels, from altering rates of biochemical reactions to determining sustainability of entire ecosystems. Although extended exposure to elevated temperatures influences organismal phenotypes important for human health, agriculture, and ecology, the molecular mechanisms that drive these responses remain largely unexplored. Prolonged, mild temperature stress $\left(48 \mathrm{~h}\right.$ at $\left.28^{\circ} \mathrm{C}\right)$ has been shown to inhibit reproduction in Caenorhabditis elegans without significantly impacting motility or viability.

Results: Analysis of molecular responses to chronic stress using RNA-seq uncovers dramatic effects on the transcriptome that are fundamentally distinct from the well-characterized, acute heat shock response (HSR). While a large portion of the genome is differentially expressed $\geq 4$-fold after $48 \mathrm{~h}$ at $28^{\circ} \mathrm{C}$, the only major class of oogenesis-associated genes affected is the vitellogenin gene family that encodes for yolk proteins (YPs). Whereas YP mRNAs decrease, the proteins accumulate and mislocalize in the pseudocoelomic space as early as $6 \mathrm{~h}$, well before reproduction declines. A trafficking defect in a second, unrelated fluorescent reporter and a decrease in pre-synaptic neuronal signaling indicate that the YP mislocalization is caused by a generalized defect in endocytosis. Molecular chaperones are involved in both endocytosis and refolding damaged proteins. Decreasing levels of the major HSP70 chaperone, HSP-1, causes similar YP trafficking defects in the absence of stress. Conversely, increasing chaperone levels through overexpression of the transcription factor HSF-1 rescues YP trafficking and restores neuronal signaling.
\end{abstract}

Conclusions: These data implicate chaperone titration during chronic stress as a molecular mechanism contributing to endocytic defects that influence multiple aspects of organismal physiology. Notably, HSF-1 overexpression improves recovery of viable offspring after exposure to stress. These findings provide important molecular insights into understanding organismal responses to temperature stress as well as phenotypes associated with chronic protein misfolding.

Keywords: Heat shock response, Chronic stress, Endocytosis, Trafficking, Chaperones

\footnotetext{
* Correspondence: eguisbert@fit.edu

Department of Biomedical and Chemical Engineering and Sciences, Florida Institute of Technology, Melbourne, FL, USA
}

(c) The Author(s). 2021 Open Access This article is licensed under a Creative Commons Attribution 4.0 International License, which permits use, sharing, adaptation, distribution and reproduction in any medium or format, as long as you give appropriate credit to the original author(s) and the source, provide a link to the Creative Commons licence, and indicate if changes were made. The images or other third party material in this article are included in the article's Creative Commons licence, unless indicated otherwise in a credit line to the material. If material is not included in the article's Creative Commons licence and your intended use is not permitted by statutory regulation or exceeds the permitted use, you will need to obtain permission directly from the copyright holder. To view a copy of this licence, visit http://creativecommons.org/licenses/by/4.0/ The Creative Commons Public Domain Dedication waiver (http://creativecommons.org/publicdomain/zero/1.0/) applies to the data made available in this article, unless otherwise stated in a credit line to the data. 


\section{Background}

The fate of an organism can rest on its ability to accurately sense and respond to stress. A ubiquitous stress that often disrupts homeostasis is temperature fluctuation [1]. Consequently, biological systems have a variety of mechanisms to re-establish homeostasis when faced with elevated temperatures. These adaptations to temperature can be both evolutionary and organismal. Evolutionary adaptations are driven by selection of heritable genetic changes. Organismal responses are driven by cellular and molecular mechanisms.

At the organismal level, animals exhibit changes in behavior, autonomic reflexes (e.g., sweating), cardiovascular function, and neuroendocrine signaling when exposed to elevated temperatures [2]. For livestock, temperature is one of the largest stressors in animal production, and organismal response mechanisms are typically detrimental to performance due to their high metabolic costs $[3,4]$. Heat stress decreases growth, reproduction, milk production, and meat production, while increasing the occurrence of disease. Furthermore, organisms have evolved to survive specific ranges of temperatures, and an increase of only a few degrees is predicted to result in the extinction of as many as $16 \%$ of all species [5].

At the molecular level, elevated temperatures disrupt protein-folding homeostasis, or proteostasis [6]. Proteostasis is normally maintained by an extensive network of factors collectively known as the proteostasis network, which includes pathways that regulate the synthesis, folding, trafficking, and degradation of proteins. However, many proteins adopt native states that are only marginally stabilized, such that an increase of only $4{ }^{\circ} \mathrm{C}$ destabilizes the average protein by $\sim 20 \%$ in Escherichia coli [7]. To deal with the massive accumulation of misfolded proteins during temperature stress, all organisms utilize an adaptative response known as the heat shock response (HSR) [8]. This highly conserved pathway is mediated by the transcription factor heat shock factor 1 (HSF1). Mutations in HSF1 cause thermosensitivity, whereas overexpression of HSF1 enhances thermotolerance $[9,10]$.

An important class of HSF1-regulated genes is the molecular chaperone family that assists in protein folding $[11,12]$. In the absence of stress, chaperones participate in de novo folding of newly synthesized proteins and in cellular processes that require assembly and disassembly of macromolecular complexes. For example, chaperones are required for several steps of endocytosis [13-15]. The initial invaginations of coated pits, dissociation of clathrin during vesicle uncoating, and the stabilization of clathrin after dissociation are regulated by the chaperone HSC70. Another chaperone, RME-8, is important for downstream steps of clathrin-mediated endocytosis and is a shared regulator of both receptor-mediated endocytosis (RME) in oocytes and fluid-phase endocytosis in coelomocytes in Caenorhabditis elegans [16-19]. In the presence of stress, chaperones help to repair misfolded or damaged proteins [20]. This serves to titrate specific chaperones away from an inhibitory complex with HSF1. Therefore, the activity of HSF1 is intimately linked to the protein-folding state of the cell. Conditions other than temperature stress similarly lead to chaperone titration. During aging, a substantial decline in the capacity of the proteostasis network is attributed to age-associated accumulation of misfolded proteins [21]. Numerous neurodegenerative diseases are also associated with extended chaperone titration [22].

The consequences of stress are fundamentally distinct depending on the degree and duration of the stress. The HSR has been extensively studied at the molecular level using a variety of model systems exposed to acute, severe temperature stress. However, physiological responses to temperature stress in metazoans are typically observed during mild stress on much longer timescales. The connection between the molecular events that take place during acute stress and the organismal-level responses to chronic stress remains to be fully characterized. Recently, correlations have been made between molecular and organismal responses to temperature stress. For example, we have shown that a chronic, 4-week exposure to thermal stress in Hippocampus erectus seahorses results in altered feeding frequency and overall ventilation rates, along with increased expression of HSR genes and genes involved in regulating reproduction [23]. Additionally, the advent of next-generation sequencing and genomic information has enabled a multitude of studies to examine transcriptomic responses to temperature stress in a variety of metazoans [24-26]. While these studies generate a treasure trove of data, this methodology is limited to providing descriptive correlations.

The multicellular, transparent nematode $C$. elegans is an ideal candidate for examining the effects of temperature stress at the molecular, cellular, tissuespecific, and organismal levels. An acute, nearly lethal temperature stress $\left(1 \mathrm{~h}\right.$ at $\left.33-35^{\circ} \mathrm{C}\right)$ that elicits the HSR has no reported ill effects on organismal fecundity in $C$. elegans [27-29]. In contrast, a chronic, mild temperature stress $\left(48 \mathrm{~h}\right.$ at $28^{\circ} \mathrm{C}-\mathrm{a}$ few degrees above the normal growth temperatures of $15-25^{\circ} \mathrm{C}$ ) completely inhibits reproduction while only mildly affecting phenotypes such as viability and motility $[30,31]$. Here, we combine genetics and transcriptomic analyses with cellular and organismal phenotypes to identify molecular mechanisms driving the dramatic differences in fate between acute and chronic stress. 


\section{Results}

\section{Chronic heat stress inhibits egg laying and elicits distinct} transcriptomic responses

Previous studies have shown that worms display a reproductive defect after prolonged exposure to mild heat stress (HS) $[30,31]$. The temperature shifts in those studies were initiated prior to the onset of egg laying. However, more recent work showed that multiple stress responses attenuate at the onset of egg laying, such that stress-inducible gene expression in reproductive adults is half that of prereproductive worms [32]. Therefore, we first established organismal responses to chronic temperature stress after this final stage of development. Egg-laying adults were evaluated for reproduction and motility over a 2-day HS time course that reflects $\sim 10 \%$ of the C. elegans lifespan. Worms exposed to $28^{\circ} \mathrm{C}$ HS laid similar numbers of eggs as the control worms $\left(20^{\circ} \mathrm{C}\right)$ during the first $12 \mathrm{~h}$, but only $\sim 40 \%$ as many eggs between the 12- and 24-h HS timepoints (Fig. 1a). After the 24-h timepoint, the HS worms had essentially ceased reproduction. Despite the shutdown of reproduction, worms displayed no other obvious defects. This suggests that reproduction was not inhibited as a result of a catastrophic decline in worm health. To quantitatively assess whether chronic HS impacted motility, we used a thrashing assay. Exposure to $28^{\circ} \mathrm{C} \mathrm{HS}$ did not affect motility after $24 \mathrm{~h}$ and only had a slight effect (<15\%) after $48 \mathrm{~h}$ (Fig. 1b). Therefore, a dramatic loss of reproductive capacity but not motility is evident during chronic temperature stress after the onset of egg laying.

To identify molecular changes in these chronic stress conditions, the transcriptome was characterized using RNA-sequencing from three biological replicates at four timepoints: $0 \mathrm{~h}\left(20^{\circ} \mathrm{C}\right.$ control $), 1 \mathrm{~h}, 24 \mathrm{~h}$, and $48 \mathrm{~h}$ at $28^{\circ} \mathrm{C}$ HS. These timepoints were selected to compare the effects of acute (1-h) and chronic (24- and 48-h) exposures to $28^{\circ} \mathrm{C} \mathrm{HS}$, based on the distinct phenotypic changes observed in reproduction and motility. Each sample generated between 39 and 59 million clean reads, with 5.91 to $8.98 \mathrm{G}$ of clean bases. The samples each had a Q20 score > 97.4\% and the Pearson correlation coefficients between the biological replicates ranged between 0.973 and 0.994 , indicating high sequencing quality and reproducibility. Differentially expressed genes were identified using the DESeq R package comparing each HS timepoint to the 0h $20^{\circ} \mathrm{C}$ controls (see Additional file 1) [33]. Genes with an adjusted (Benjamini-Hochberg) $p$ value $<0.05$ were considered differentially expressed [34].

Analysis of the RNA-seq data revealed that $1 \mathrm{~h}$ at $28^{\circ} \mathrm{C}$ caused differential expression of only a few genes (10 genes down-regulated; 12 genes up-regulated) (Fig. 1c). The down-regulated genes are largely uncharacterized, but include three genes with predicted solute carrier activity, two with predicted roles in coenzyme A processes, and several with predicted catalytic activity. The up-regulated genes include six heat shock proteins (HSPs) as expected, as well as four genes of unknown function and two genes with diverse roles (ckb-2 and cebp-1). This dataset, while using a duration commonly used for acute HS (1 h), is distinct from standard acute HS protocols that employ higher temperatures and observe larger changes in gene expression. In contrast, $24 \mathrm{~h}$ of $28^{\circ} \mathrm{C} \mathrm{HS}$ led to downregulation of 4755 genes and up-regulation of 4775 genes (Fig. 1d). Approximately $28 \%$ of the differentially expressed genes (697 genes down; 1934 genes up) experienced $\mathrm{a} \geq 4$-fold change in expression. The $48-\mathrm{h} 28^{\circ} \mathrm{C} \mathrm{HS}$ led to down-regulation of 4365 genes and up-regulation of 4770 genes (Fig. 1e), 33\% of which (749 genes down; 2303 genes up) were altered by $\geq 4$-fold. Venn diagrams showed that all of the genes differentially expressed during 1 -h $28{ }^{\circ} \mathrm{C}$ HS were shared with at least one of the longer HS conditions, whereas $30 \%$ of the $24-\mathrm{h}$ and $27 \%$ of the $48-\mathrm{h} 28^{\circ} \mathrm{C}$ HS genes were uniquely regulated by those timepoints (see Additional file 2: Fig. S1 and Additional file 3). Together, these data reveal extensive, duration-specific remodeling of the transcriptome in response to chronic stress. Furthermore, the molecular responses to chronic, mild temperature stress extend beyond the well-characterized heat shock response (HSR). Only $8 \%$ of the genes regulated during 48 -h $28^{\circ} \mathrm{C}$ HS were shared with a previously published gene set representing a classical acute HSR [35] (see Additional file 2: Fig. S2 and Additional file 3).

To determine which cellular pathways were affected during chronic HS, gene ontology (GO) enrichment analysis was used (see Additional file 2: Fig. S3 and Additional file 3) [36, 37]. The 24-h HS gene enrichments showed an up-regulation in stress responses, such as defense and immune system responses, along with down-regulation of metabolic processes and nucleotide binding. Interestingly, both the 24-h and the 48-h HS timepoints elicited down-regulation of genes associated with the structural constituent of the cuticle, with the 48-h HS also up-regulating many cuticle-associated genes, suggesting a cuticle restructuring event in response to chronic HS.

The most dramatic phenotypic effect of chronic stress is inhibition of egg laying. If the reproductive cessation during chronic HS was being driven by transcriptional shutdown of oogenesis, we would expect to see a general repression of these genes. However, GO analyses did not reveal enrichment for reproduction-associated processes. To investigate this further, the genes involved in reproduction were specifically queried by examining the expression levels of oogenesis-enriched genes, as described by Reinke et al. [38]. Together, the 920 oogenesis-enriched genes identified in our RNA-seq data showed no change in expression at the 1-h timepoint, slight repression at $24 \mathrm{~h}$, and a smaller degree of 


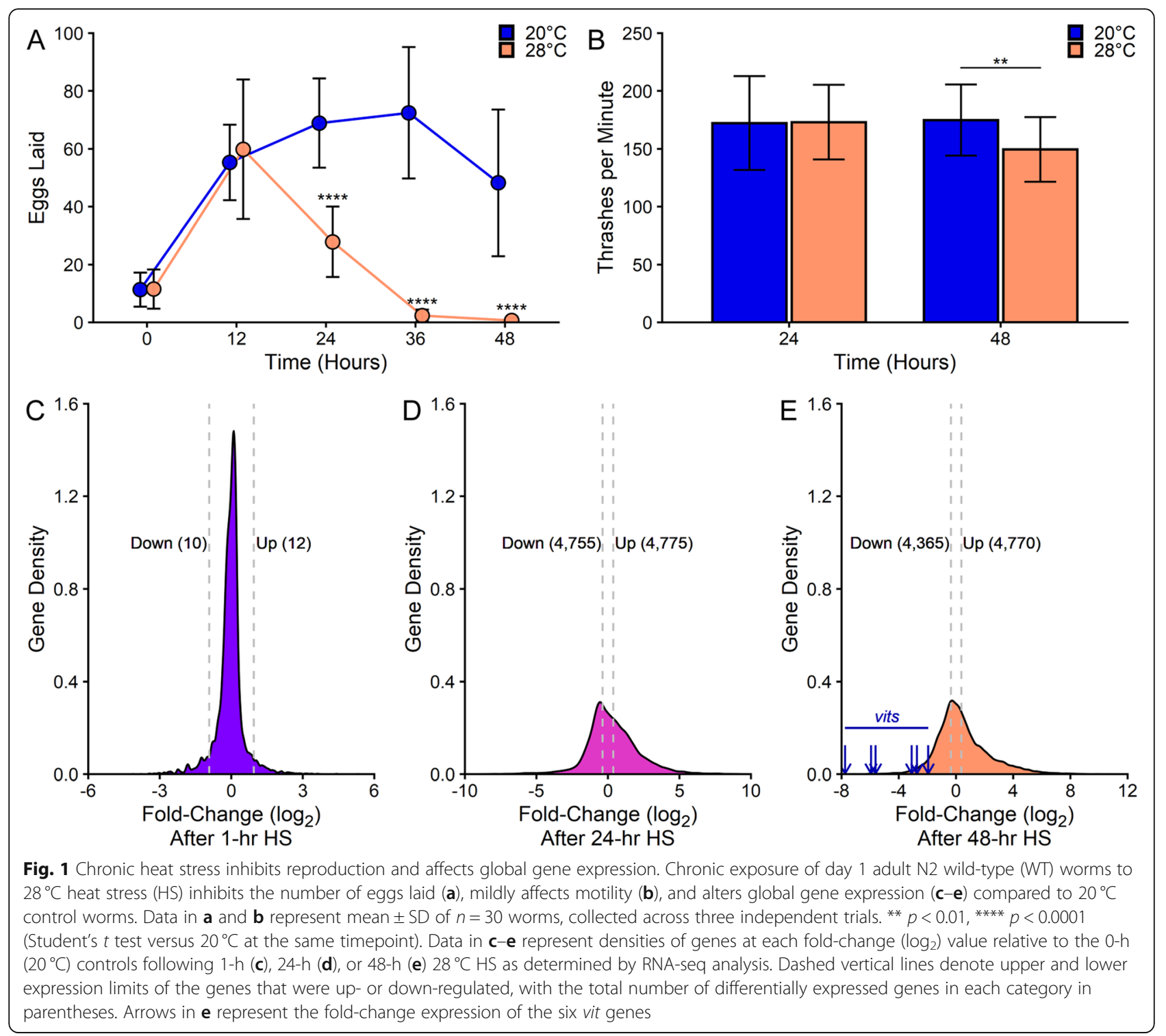

repression at the 48-h HS timepoint (see Additional file 2: Figs. S4A-C). Among these genes, $\sim 3.8 \%$ were affected at least 4-fold by exposure to $28^{\circ} \mathrm{C}$ HS for 24 or $48 \mathrm{~h}$. Therefore, our data indicate that the cessation of reproduction during chronic HS does not involve an overall shutdown of oogenesis-enriched gene expression.

\section{Chronic heat stress disrupts endocytosis of yolk by oocytes}

Among the most strongly repressed genes at the 48-h HS timepoint was the six-member vitellogenin gene family (vit-1 through vit-6) that encodes the yolk proteins (YPs) (Fig. 1e, arrows), with levels ranging from a 3.9-fold to 216.8-fold decrease in expression compared to controls. The vit genes and their YP products play important roles in providing nutrients to developing oocytes [39-41]. In C. elegans, the six vit genes produce three major YP species-YP170, YP115, and YP88-that are named according to their molecular weights (see schematic in Fig. 2a). The YP170 species is composed of two protein products: YP170A, encoded by vit-3, vit-4, and vit-5; and YP170B, encoded by vit-1 and vit-2. The other two protein species-YP115 and YP88-are cleaved in the pseudocoelom (body cavity) from a 180$\mathrm{kDa}$ precursor protein produced by vit-6 [42, 43].

Since vit expression was decreased during chronic HS, YP levels were analyzed by SDS-PAGE to determine whether they also decreased $[44,45]$. In contrast to the repression of YP mRNA levels, chronic 24- and 48-h HS led to accumulation of all three major YP species when compared to age-matched controls (Fig. 2b). YP identities were validated by comparison with a mutant known to accumulate YPs (compare YP170::GFP;rme-4 mutants to YP170::GFP;WT in Fig. 2b) [46]. 

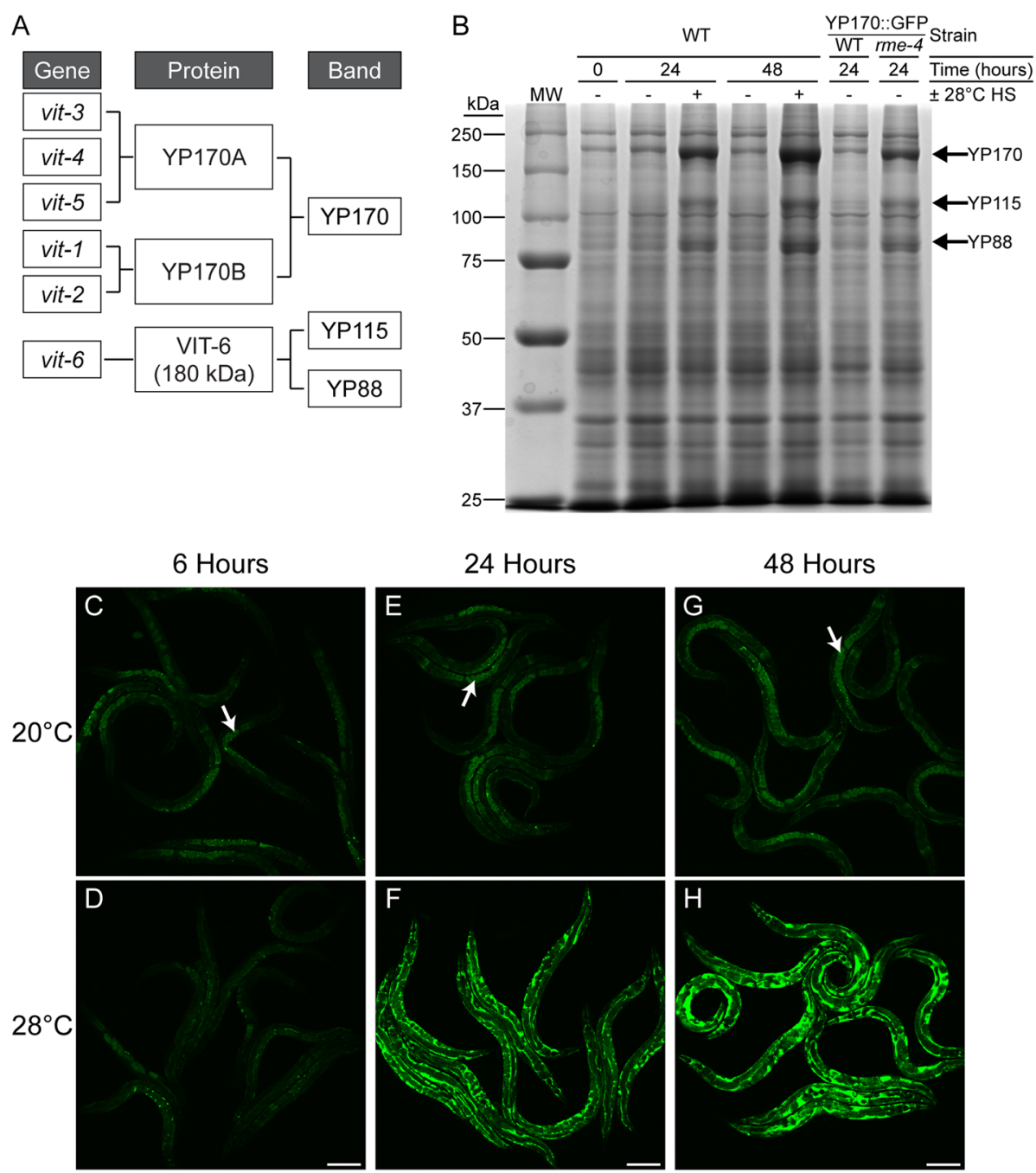

Fig. 2 Chronic heat stress causes yolk protein accumulation and mislocalization. a A schematic showing the relationship between the six vit genes, their initial protein products, and the three major yolk protein (YP) bands. $\mathbf{b}$ Coomassie-stained SDS-PAGE reveals accumulation of all three major YP species following chronic exposure to $28^{\circ} \mathrm{C}$ HS. Arrows indicate YP170, YP115, and YP88 bands. The rme-4(b1001) mutant YP170:GFP strain (RT362) was included for YP band identification. Shown is a representative image from three independent trials. MW: molecular weight marker; WT: wild-type. $\mathbf{c}-\mathbf{h}$ Chronic exposure to $28^{\circ} \mathrm{C}$ HS causes accumulation and mislocalization of the YP170::GFP (RT130) fluorescent reporter. Arrows in $\mathbf{c}, \mathbf{e}$, and $\mathbf{g}$ demonstrate proper localization of YP170::GFP in embryos at the control temperature. Shown are representative images from three independent trials with $n \geq 10$ worms in each trial. Scale bar: $150 \mu \mathrm{m}$

The striking accumulation of YPs seen in adults could occur in one of the three locations involved in the YP trafficking pathway: the intestine (site of synthesis), the embryos (site of uptake), or the pseudocoelomic space that separates the intestine from the gonad $[44,47,48]$. To determine the location of YP accumulation, a fluorescent reporter containing YP170 fused with GFP (YP170::GFP) was used (Fig. 2c-h) [47]. Compared to $20^{\circ} \mathrm{C}$ controls, where YP170::GFP was localized in the oocytes (see arrows in Fig. 2c, e, g), exposure to $28^{\circ} \mathrm{C} \mathrm{HS}$ for $24 \mathrm{~h}$ (Fig. 2f) or $48 \mathrm{~h}$ (Fig. 2h) resulted in increased levels of YP170::GFP in the pseudocoelom but not in the intestine or the oocytes (see Additional file 2: Fig. S5 for higher magnification at the 24-h timepoint). As oocytes normally take in yolk using receptor-mediated endocytosis, the pseudocoelomic accumulation of YPs during HS phenocopies mutations in endocytosis [47]. Importantly, this phenotype can be observed after a 6-h HS exposure, with prominent YP170::GFP puncta around the embryos and reduced YP170::GFP intensity inside the embryos compared to the $20^{\circ} \mathrm{C}$ controls (Fig. 2c vs $2 \mathrm{~d}$ ). This finding revealed that YP accumulation preceded, and was therefore not a consequence of, the egg-laying defect that developed between 12 and $24 \mathrm{~h}$ of HS. 


\section{Chronic heat stress disrupts endocytosis in coelomocytes and affects neuronal signaling}

To determine whether disruption of YP trafficking is indicative of a generalized defect in trafficking, an independent protein trafficking reporter was used. This reporter contains a muscle-specific myosin promoter that drives a GFP transgene containing a signal sequence (myo-3p::ssGFP). The ssGFP is secreted from the muscles into the pseudocoelom and then taken up via fluidphase endocytosis into the six macrophage-like coelomocytes, where its fluorescence is readily observable [19]. Whereas fluorescence was localized in the coelomocytes at the control temperature (Fig. 3a, c), exposure of this reporter to 24- or $48-\mathrm{h} 28^{\circ} \mathrm{C}$ HS resulted in diffuse fluorescence across the pseudocoelom (Fig. 3b, d). Thus, this protein trafficking reporter with a distinct endocytic process revealed a second trafficking defect in a different target tissue.

However, trafficking of the myo-3p::ssGFP reporter could be indirectly affected by the high levels of accumulated $\mathrm{YP}$ in the pseudocoelomic space during chronic stress. To test this, we knocked down YP in the myo-3p:: ssGFP reporter strain using RNA interference (RNAi) against ceh-60, a regulator of vitellogenin expression [49, 50]. While ceh-60 RNAi effectively knocked down YP in the YP170::GFP reporter, which showed little to no GFP fluorescence (see Additional file 2: Figs. S6E-H), it did not affect the coelomocyte trafficking defect in the myo3p::ssGFP reporter during exposure to $24-\mathrm{h} 28^{\circ} \mathrm{C}$ HS (Additional file 2: Figs. S6A-D). These results indicate that yolk accumulation in the pseudocoelom does not inhibit coelomocyte uptake and that a general defect in endocytosis occurs during chronic stress.

If endocytosis is globally disrupted during chronic stress, then neuronal signaling, which is heavily dependent on endocytosis, would also be affected. Such a defect would localize to the pre-synaptic junctions that rely on clathrinmediated endocytosis to recycle synaptic vesicle components [51-53] (see schematic in Fig. 3e). Disruption of pre-synaptic versus post-synaptic neuronal signaling can be distinguished by sensitivity to the paralysis-inducing drugs aldicarb, an acetylcholinesterase inhibitor that acts on pre-synaptic signaling, and levamisole, a nicotinic acetylcholine receptor agonist that acts on post-synaptic signaling [54, 55]. Exposure to $48-\mathrm{h} 28^{\circ} \mathrm{C}$ HS caused a dramatic reduction in sensitivity to aldicarb, with $\sim 36 \%$ of the stressed worms showing aldicarb resistance (not paralyzed) compared to only $\sim 19 \%$ of the control worms remaining motile (Fig. 3f). In contrast, no difference was observed in the sensitivity to levamisole between the unstressed controls and the heat-stressed worms. These data suggest a pre-synaptic signaling defect during chronic stress, which supports the hypothesis that chronic stress globally disrupts endocytosis.

\section{Heat shock factor 1 (HSF-1) overexpression rescues chronic stress-induced endocytic disruptions}

Several steps in endocytosis are dependent on molecular chaperones for assembly and disassembly of macromolecular complexes $[14,15]$. These molecular chaperones are also important for protein folding during temperature stress and are responsible for negative regulation of the HSR in the absence of stress [11]. Activation of the HSR in our transcriptomic data indicates that chaperones are titrated by misfolded proteins during chronic stress. Therefore, we hypothesized that titration of chaperones away from their constitutive roles in endocytosis could be the mechanism causing disruption of protein trafficking and subsequent organismal phenotypes during chronic stress.

If chaperone titration disrupts endocytosis, then reducing or increasing chaperone levels would exacerbate or suppress endocytic defects, respectively. To test this, we first inhibited the predominant cellular HSP70 chaperone, hsp-1, using RNAi knockdown. At the control temperature of $20^{\circ} \mathrm{C}$, knockdown of $h s p-1$ in the YP170:: GFP reporter resulted in pseudocoelomic YP accumulation that mirrored chronic HS (Fig. 4). Therefore, depletion of HSP70 disrupts YP trafficking, consistent with previous reports demonstrating the role of HSP70 in endocytosis in other systems [13-15].

Next, we tested the effects of increased HSP levels by using worms overexpressing the transcription factor heat shock factor 1 (HSF-1) [56]. To determine whether YP levels in the embryos were affected by chaperone levels, we collected equal numbers of eggs from wild-type and HSF-1 overexpression adults with and without HS. Consistent with a defect in endocytosis, isolated wild-type embryos contained lower levels of YPs per egg upon chronic stress (Fig. 5a). Quantitation of this effect showed that wild-type embryos had a 50\% reduction in YP170 uptake capacity during HS (Fig. 5b). Remarkably, HSF-1 overexpression effectively restored embryonic YP accumulation, with these embryos maintaining 98\% of their YP170 uptake capacity. YP115 and YP88 also showed similar trends of rescue. However, HSF-1 overexpression was not sufficient to rescue YP accumulation inside adults during stress (Fig. 5a). Together, these results indicate that overexpression of chaperones is sufficient to rescue the YP endocytosis defect in oocytes during chronic stress.

We next tested whether chaperone titration represents a mechanism that generally affects cellular endocytosis by examining the effects of HSF-1 overexpression on neuronal signaling. HSF-1 overexpression reversed the aldicarb resistance induced by $48 \mathrm{~h}$ at $28^{\circ} \mathrm{C}$ (Fig. 5c). Therefore, overexpression of HSF-1 can rescue multiple endocytosis defects and is not specific to YPs. The effects of HSF-1 overexpression are presumably through 

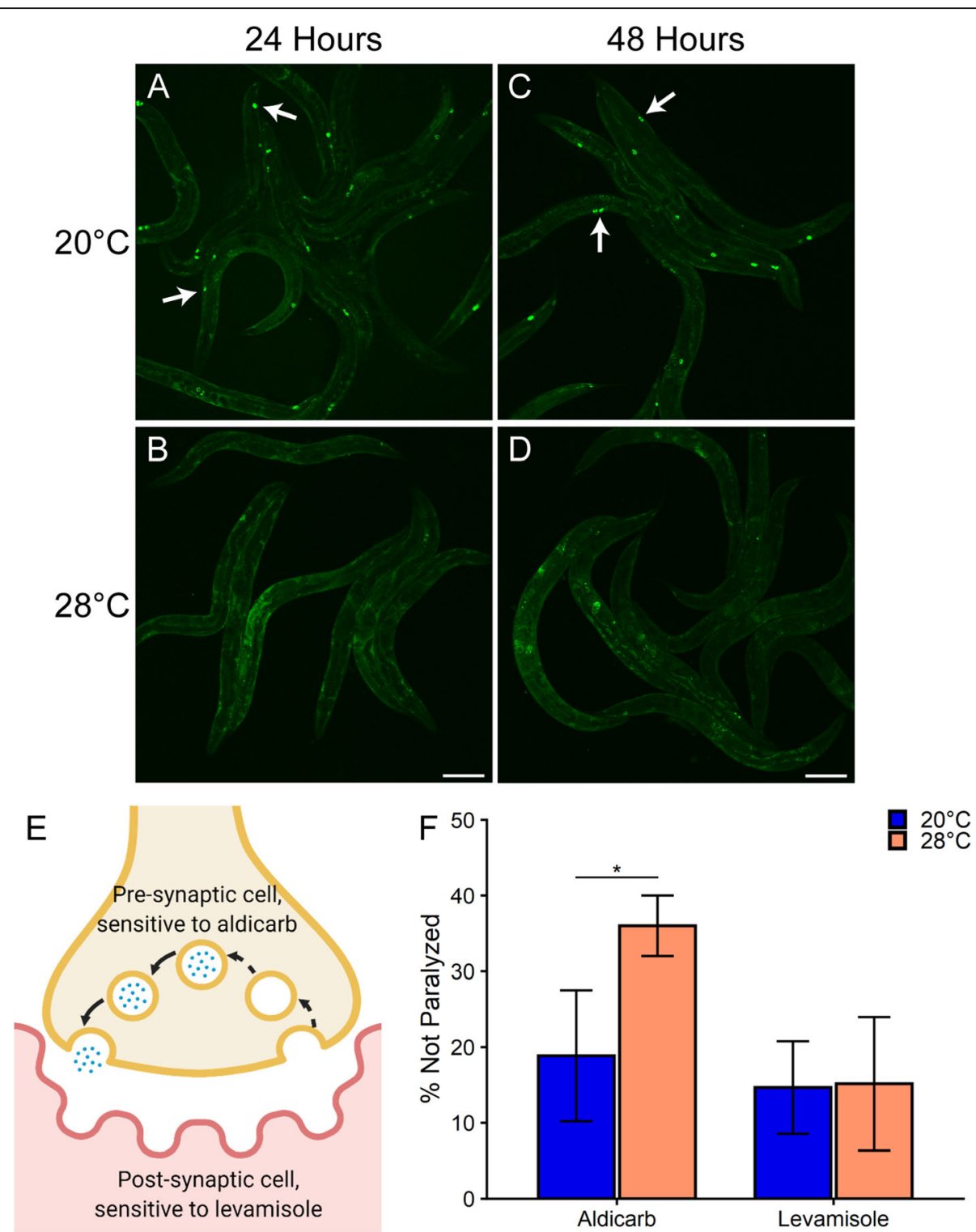

Fig. 3 Chronic heat stress inhibits endocytosis in coelomocytes and disrupts neuronal signaling. a-d Chronic exposure to $28^{\circ} \mathrm{C} H S$ (b and $\mathbf{d}$ ) disrupts coelomocyte endocytosis compared to $20^{\circ} \mathrm{C}$ controls (a and c) as observed in myo-3p::ssGFP (GS1912) adults. Shown are representative images from three independent trials with $n \geq 10$ worms. Arrows in $\mathbf{a}$ and $\mathbf{c}$ demonstrate proper localization of ssGFP in coelomocytes at the control temperature. Scale bar: $150 \mu \mathrm{m}$. e A schematic showing the cycle of synaptic vesicle formation and neurotransmitter release at a neuromuscular junction. Synaptic vesicle components are normally recycled through endocytosis (dashed arrows). $\mathbf{f}$ Exposure of WT (N2) adults to $48-\mathrm{h} 28^{\circ} \mathrm{C} \mathrm{HS}$ increases resistance to aldicarb, but not to levamisole, compared to $20^{\circ} \mathrm{C}$ controls as measured using paralysis assays. Data represent the mean \pm SD of $n=3$ independent trials. ${ }^{*} p<0.05$ (Student's $t$ test)

upregulation of chaperones; however, this data does not exclude other pathways regulated by HSF-1. Interestingly, no significant differences in aldicarb sensitivity were observed in wild-type or HSF-1 overexpression worms after $24-\mathrm{h} 28^{\circ} \mathrm{C}$ HS. This indicates that neuronal signaling is more resistant to stress-induced changes than the other pathways that showed endocytic defects at this timepoint.

Given that HSF-1 overexpression restored the endocytic defect in oocytes and the neuronal phenotype in adults, we next examined whether HSF-1 overexpression could protect reproductive output during chronic HS. Although HSF-1 overexpression was not sufficient to restore egg laying during continuous $28^{\circ} \mathrm{C}$ HS, it did enhance recovery of viable offspring after a 24-h exposure to $28^{\circ} \mathrm{C} \mathrm{HS}$ (Fig. $5 \mathrm{~d}$ ). In these conditions, $100 \%$ of adults from both the wild-type and HSF-1 overexpression strains laid eggs during a $20^{\circ} \mathrm{C}$ recovery period, but the HSF-1 overexpression worms laid significantly more eggs (Fig. 5e) and produced more larvae (Fig. 5f). 


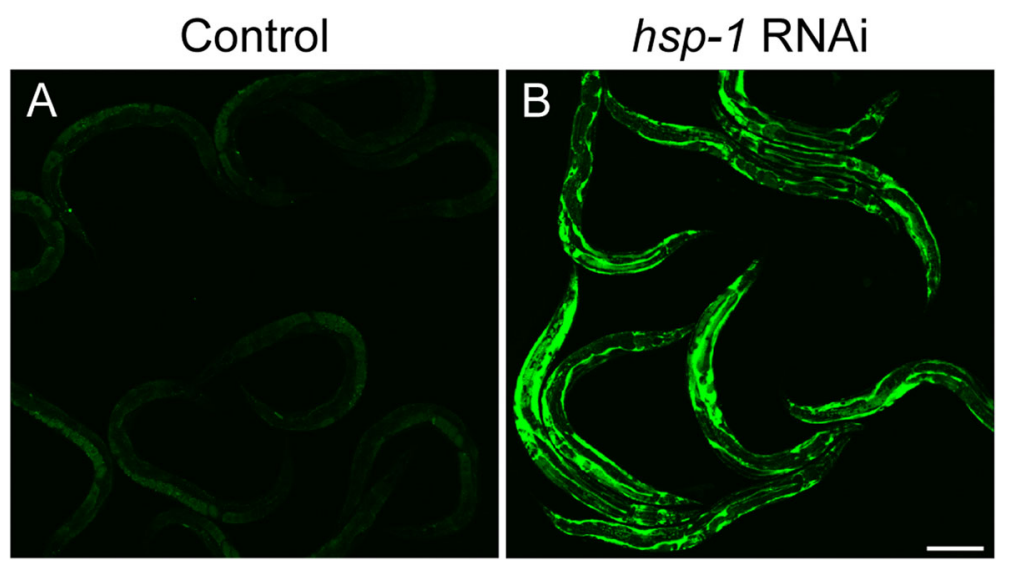

Fig. 4 hsp-1 knockdown inhibits yolk endocytosis. hsp-1 knockdown causes yolk to accumulate in the pseudocoelomic space, as shown in YP170::GFP (RT130) worms that were raised to the $L 4$ stage on OP50 and then exposed to either $\mathbf{a}$ control ( $L 4440$, empty vector) or $\mathbf{b} h s p-1$ RNAi for $48 \mathrm{~h}$ at $20^{\circ} \mathrm{C}$. Shown are representative images from three independent trials with $n \geq 10$ worms. Scale bar: $150 \mu \mathrm{m}$

Notably, only HSF-1 overexpression worms were capable of producing viable offspring in the first $24 \mathrm{~h}$ of recovery, whereas wild-type worms did not produce viable offspring until the second day of recovery (see Additional file 2: Fig. S7). These data suggest that increased chaperone levels can provide a stronger recovery of viable offspring following a period of chronic HS. Together, the recovery of YP endocytosis, neuronal signaling, and viable offspring indicate that a persistent disruption of proteostasis during chronic stress titrates chaperones and that this is a common molecular mechanism that contributes to multiple physiological processes.

\section{Discussion}

We have identified chaperone titration as a molecular mechanism that contributes to a range of cellular and organismal phenotypes during exposure to chronic temperature stress $\left(28^{\circ} \mathrm{C}\right)$ (Fig. 6). The organismal phenotypes include cessation of egg laying and altered neuronal signaling. The cellular phenotypes include inhibition of YP uptake by oocytes and fluid-phase endocytosis by coelomocytes. A common feature of these phenotypes is their dependence on endocytosis. Our data indicate that chronic but mild temperature stress titrates chaperones away from their constitutive roles in endocytosis. Validating this model, induction of chaperones through HSF-1 overexpression partially rescues these phenotypes. Together, this work uncovers a unifying mechanism that connects molecular, cellular, tissue-specific, and organismal responses to chronic temperature stress.

Recent experiments have suggested that inhibition of endocytosis via chaperone titration plays an important role in multiple neurodegenerative diseases [57]. It was shown that ectopic expression of disease-associated, aggregation-prone proteins in cultured cells leads to endocytic disruptions that can be rescued by chaperone overexpression. Here, we demonstrate that a general temperature stress can have the same effects on chaperones and endocytosis as those seen with specific aggregation-prone proteins. Therefore, our work extends the model of chaperone titration-induced endocytic defects to an intact organism. Furthermore, the discovery that chaperone titration is a shared mechanism may help to explain why neurodegenerative diseases have such a large environmental component.

Our investigation has also uncovered critical spatiotemporal aspects of the responses to chronic temperature stress. A uniform, mild stress affects several processes central to organismal health, but at different timescales and with varying degrees of severity. The first observed phenotype in response to $\mathrm{HS}$ is a disruption of yolk trafficking into embryos seen in the first $6 \mathrm{~h}$ of $28^{\circ} \mathrm{C}$ HS. By $24 \mathrm{~h}$ of $\mathrm{HS}$, egg laying is terminated and fluid-phase endocytosis in coelomocytes is compromised. After $48 \mathrm{~h}$ of HS, neuronal signaling in response to aldicarb is altered and motility is slightly decreased. Thus, different tissues display unique temporal sensitivities to a stress applied uniformly to the organism. Distinct tissue-specific responses have also been observed through genetic disruption of protein folding, as tissues maintain unique balances between components of the proteostasis network and their tissuespecific substrates [58]. In addition, protein-misfolding mutations in a broadly expressed protein can elicit a "bystander" effect whereby the folding and trafficking of a specific but unrelated protein can be disrupted, possibly through titration of a selective, shared chaperone [59]. This effect was shown to produce cell-specific phenotypes despite the ubiquitous expression of the mutated protein. Recent work has also suggested cell-specific requirements for broad-specificity chaperones [60]. Therefore, the chronic stress-mediated phenotypes uncovered here 


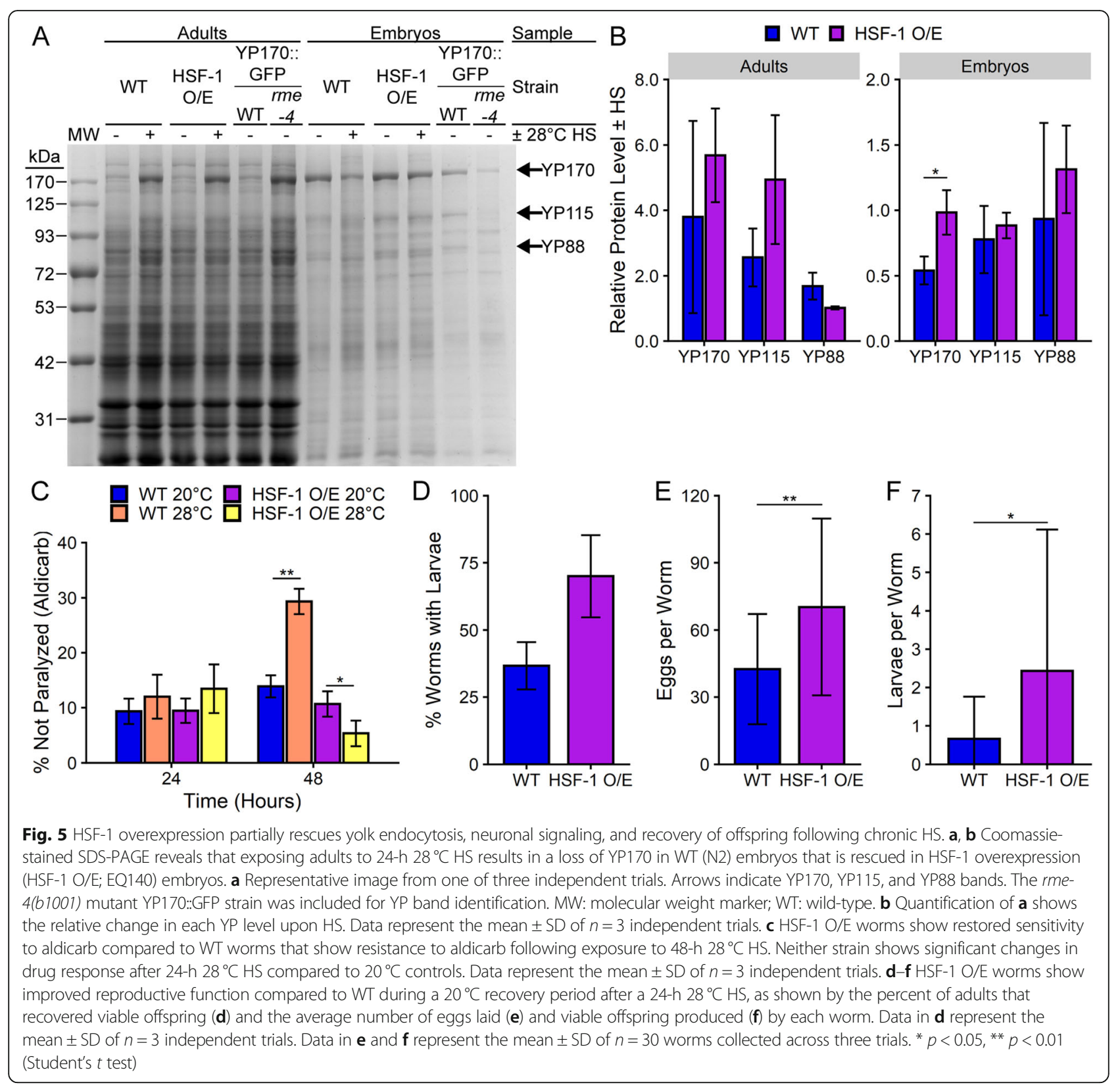

contribute to the growing recognition of a range of cellular proteostasis capacities existing within an organism.

The earliest observed chronic stress phenotype, YP mislocalization at $6 \mathrm{~h}$, precedes the reproductive defect. However, the reproductive defect is not likely to be caused by YP mislocalization alone, since YPs are not required for oogenesis, fertilization, or egg laying. Several mutations that block YP production do not affect egg laying, and mutations in the yolk receptor (RME-2) do not prevent production of viable offspring $[47,49,61]$. The observation that HSF-1 overexpression partially rescues reproduction after $24 \mathrm{~h}$ of stress indicates that chaperone titration contributes to the reproductive defect independently of yolk trafficking. However, since the rescue is not complete, there must be additional mechanisms behind this reproductive cessation. As temperature stress also disrupts embryonic development [62], these other mechanisms could include signaling pathways that coordinate development of the embryos with egg-laying behavior in the adult.

Notably, the repression of vit genes occurs after the YP trafficking defect. However, there is no visible accumulation of YP in the intestine, indicating that this effect is cell non-autonomous. Together, these data suggest a signaling pathway between the site of YP accumulation in the pseudocoelom and the site of synthesis in the intestine. 


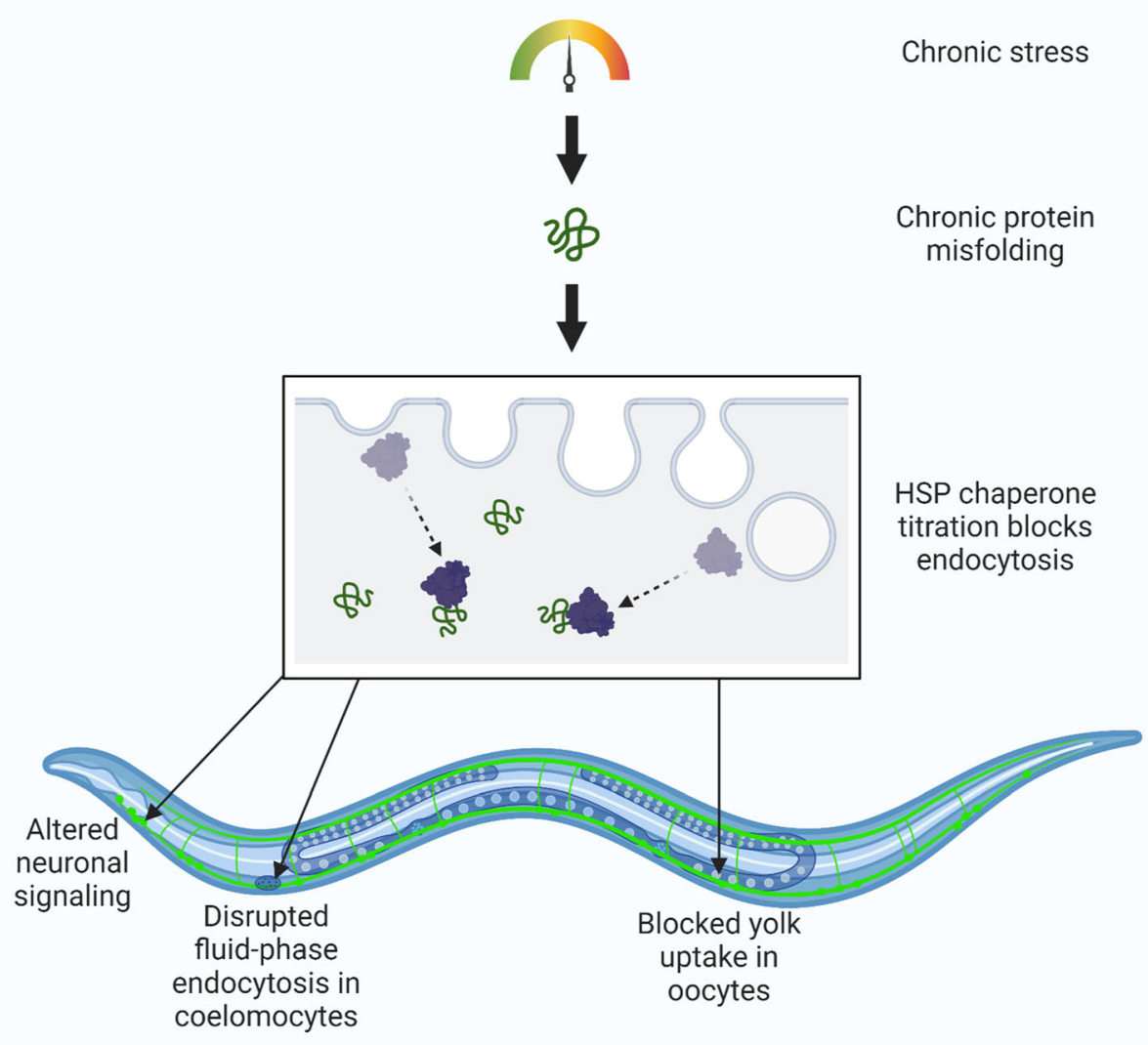

Fig. 6. Chaperone titration and disrupted endocytosis link chronic heat stress with organismal phenotypes. Chronic protein-folding stress causes a titration of chaperones and subsequent disruption in endocytosis across cell types, ultimately leading to diverse physiological defects. Here, we provide evidence of this process in endogenous yolk levels and a fluorescent yolk reporter for embryos, a GFP reporter for coelomocytes, and functional assays for neurons coupled with HSF-1-mediated rescue of endogenous yolk uptake and neuronal signaling

The framework we have established here provides a solid foundation for further investigations into the molecular and organismal responses to elevated temperature. The impact of this research is not limited to reproduction, as we have uncovered a wealth of gene expression changes induced by chronic stress. These gene expression changes are strongly enriched for specific categories, such as collagen genes, that are associated with specific organismal biology, such as cuticle structure. Our analysis connecting organismal responses to temperature with tissue-specific, cellular, and molecular pathways has wide-ranging implications for agricultural, ecological, and evolutionary studies. Furthermore, understanding the effects of extended but mild temperature stress grows increasingly critical in the face of elevated temperatures due to climate change.

\section{Conclusions}

We have established $C$. elegans as a model organism for the systematic analysis of the effects of chronic stress. We have identified chaperone titration as a molecular mechanism that contributes to defects in protein trafficking, disruption of neuronal signaling, and cessation of reproduction during exposure to extended temperature stress.

\section{Methods}

\section{Worm strains and maintenance}

The following Caenorhabditis elegans strains were used in this study: Bristol strain N2, RT130(pwIs23[YP170::GFP]), RT362(rme-4(b1001);pwIs23[YP170::GFP]), GS1912(arIs37 [myo-3p::ssGFP + dpy-20(+)] I), and EQ140(iqIs37[pAH76(hsf-1p::myc-hsf-1)+pRF4(rol-6p::rol-6(su1006)]). Unless otherwise stated, worms were maintained at $20^{\circ} \mathrm{C}$. Worm populations were synchronized for experiments by allowing day 2 adult hermaphrodites to lay eggs for $1-1.5 \mathrm{~h}$. The synchronized egg populations were then raised at $20^{\circ} \mathrm{C}$ until day one of adulthood, after the onset of egg laying $(\sim 72 \mathrm{~h}$ post-synchronization for the N2 strain). For all heat stress (HS) experiments, plates of day 1 adults were transferred to a $28^{\circ} \mathrm{C}$ dry incubator (HS worms) for the specified time course. 


\section{Egg-counting experiments}

Synchronized wild-type (N2) worms at the late L4/young adult (YA) stage ( $\sim 58 \mathrm{~h}$ after synchronization) were singled onto $35 \mathrm{~mm}$ NGM plates seeded with $100 \mu \mathrm{L}$ OP50 and kept at $20^{\circ} \mathrm{C}$ for $12 \mathrm{~h}$ to reach egg-laying adulthood. The individuals were then transferred to fresh $35 \mathrm{~mm}$ plates and shifted to $28^{\circ} \mathrm{C}$ for $\mathrm{HS}$ or maintained at $20^{\circ} \mathrm{C}$ for control conditions (this represents the 0-h timepoint) and the eggs laid on the first plate were counted. Worms were transferred to fresh, pre-warmed plates every $12 \mathrm{~h}$ with minimal exposure $(<5$ min) to ambient temperatures.

\section{Motility assays}

Thrashing was scored at room temperature (RT) in a $10-\mu \mathrm{L}$ drop of M9 on NGM agar. Individual worms were placed into the droplet and allowed to acclimate for $30 \mathrm{~s}$, then each body bend was counted for $30 \mathrm{~s}$.

\section{RNA-sequencing}

Synchronized day 1 adult wild-type (N2) worms were either collected immediately $\left(0-\mathrm{h} 20^{\circ} \mathrm{C}\right.$ control), or shifted to $28^{\circ} \mathrm{C} \mathrm{HS}$ for 1,24 , or $48 \mathrm{~h}$ before collection. RNA was collected as described previously [63]. Library preparation, sequencing, and initial data analyses were performed by Novogene. Total RNA was poly-A selected and then subjected to 150-bp paired-end Illumina HiSeq sequencing using three biological replicates for each condition. The raw reads were filtered to remove reads with adaptor contamination, reads consisting of $>10 \%$ uncertain nucleotides, and reads where $>50 \%$ of the bases were low quality (base quality <20). The remaining clean reads $(\sim 97 \%$ for each sample) were mapped to the WBcel235 C. elegans reference genome. Approximately $92-93 \%$ of the clean reads were mapped per sample. Genes that had no mapped reads for control or HS conditions were excluded from the differential expression analysis. Differentially expressed genes were identified using DESeq (v.1.18.0) by normalizing reads based on the negative binomial distribution method and comparing each HS timepoint to the 0-h control.

\section{Fluorescence microscopy}

Worms were anesthetized in $0.5-1.0 \mathrm{mM}$ levamisole on a $3 \%$ agarose pad for imaging, as described previously [63]. Images were analyzed using EZ-C1 software, Gold Version 3.90 build 869 (Nikon Corporation, Tokyo, Japan). The range and saturation levels of each image were normalized across conditions at each timepoint to allow for direct comparisons. Each trial scored $n \geq 10$ worms per condition.

\section{SDS-PAGE and Coomassie staining}

For adult protein lysates, equal numbers of adults (50-60) from each condition were picked into microcentrifuge tubes containing $33 \mu \mathrm{L}$ Laemmli sample buffer. Samples were then boiled for $10 \mathrm{~min}$, centrifuged for $10 \mathrm{~min}$ at $14000 \times \mathrm{RPM}$ at RT, and the supernatants were transferred to fresh tubes. Equal volumes were loaded per lane.

For embryo lysates, 100-200 adults from each condition were collected, and fresh bleach solution (20\% sodium hypochlorite $+0.25 \mathrm{M} \mathrm{NaOH}$ in ultrapure $\mathrm{H}_{2} \mathrm{O}$ ) was added to each tube to dissolve the adults. After $\sim 8$ min with gentle mixing (or until adults were dissolved), embryos were washed once with M9, resuspended in $15 \mu \mathrm{L}$ M9, and then the number of eggs was counted using a dissecting scope. Samples were then mixed with 2x Laemmli sample buffer, boiled, and centrifuged before loading. Equal numbers of eggs $(\sim 800)$ were loaded per lane.

Lysates were loaded into a freshly prepared 8\% SDSPAGE. Gels were stained using Coomassie brilliant blue and imaged using a ChemiDoc ${ }^{\mathrm{Tm}}$ XRS System (Bio-Rad Laboratories Inc., Hercules, CA).

\section{Yolk protein quantification}

YP bands were identified based on comparisons to literature and validated by comparing banding patterns with RME mutants known to accumulate YPs [44-46]. Using ImageLab 6.0.0 (Bio-Rad), each gel was quantified by normalizing background levels and then calculating each adjusted YP170, YP115, and YP88 band volume relative to the total lane volume for that sample. The relative accumulation or loss of each YP was calculated by dividing the adjusted YP volume in the HS lane by the adjusted YP volume in the control lane for that timepoint.

\section{RNAi experiments}

RNA interference (RNAi) was performed against the indicated genes, with L4440 as the vector control, using feeding RNAi in E. coli HT115(DE3) [64]. RNAi clones were sequence-verified before use. RNAi against ceh-60 was initiated from egg-lay synchronization. RNAi against hsp-1 was initiated in L4 worms to avoid developmental defects and was carried out for $48 \mathrm{~h}$ at $20^{\circ} \mathrm{C}$ before imaging.

\section{Neuronal transmission assays}

Paralysis plates were made using NGM containing final concentrations of $1 \mathrm{mM}$ aldicarb (Adipogen Corporation, San Diego, CA) or $0.5 \mathrm{mM}$ levamisole (Acros Organics, Thermo Scientific, Waltham, MA). For each paralysis assay, drug plates were freshly seeded with OP50 and dried at RT for $24 \mathrm{~h}$. Then, 25 adult worms that had been exposed to $20^{\circ} \mathrm{C}$ (control) or $28^{\circ} \mathrm{C}$ (HS) for 24 or $48 \mathrm{~h}$ (as described for HS conditions) were picked to each drug plate and placed in a $20^{\circ} \mathrm{C}$ incubator. Levamisole sensitivity was scored $2 \mathrm{~h}$ after plating and aldicarb sensitivity was scored $8 \mathrm{~h}$ after plating. 
Worms were scored as paralyzed if they did not move after being gently prodded $3 \mathrm{x}$ on the head and tail with a platinum wire pick. Worms that ruptured or crawled up the sides of the drug plate were censored. The percentage of worms not paralyzed in each trial was calculated from the total number of non-censored worms for that plate.

\section{Reproduction recovery experiments}

Synchronized day 1 adult wild-type (N2) or HSF-1 overexpression (EQ140) worms were singled onto $35 \mathrm{~mm}$ OP50 plates, shifted to $28^{\circ} \mathrm{C}$ HS for $24 \mathrm{~h}$, and then shifted back down to $20^{\circ} \mathrm{C}$ for recovery. During the recovery period of up to 7 days, adults were transferred to fresh OP50 plates daily and the eggs on each plate were counted. The same plates were scored again the following day for appearance of larvae (viable offspring).

\section{Statistics and figures}

Graphs were prepared with accompanying statistics using $\mathrm{R}$ version 4.0.4 ( $\mathrm{R}$ Foundation for Statistical Computing, Vienna, Austria). A $p$ value $<0.05$ was considered statistically significant. Model figures (Figs. 3e and 6) were created with BioRender.com.

\section{Abbreviations}

HS: Heat stress; HSF: Heat shock factor; HSP: Heat shock protein; HSR: Heat shock response; RME: Receptor-mediated endocytosis; ssGFP: Signalsequence green fluorescent protein; YP: Yolk protein

\section{Supplementary Information}

The online version contains supplementary material available at https://doi. org/10.1186/s12915-021-01008-1.

Additional file 1. DEGs. Worksheet containing the DESeq output file containing statistically differentially expressed genes from each timepoint with read counts, $\log _{2}$ fold-change, and $p$-values.

Additional file 2: Figure S1-S7. File containing all supplemental figures. FigS1. Venn diagram comparing Acute (1-h), Mid (24-h), and Chronic (48-h) $28^{\circ} \mathrm{C} \mathrm{HS}$ differentially expressed genes. FigS2. Venn diagram comparing Chronic (48-h) $28^{\circ} \mathrm{C}$ HS and Classical Acute HSR differentially expressed genes. FigS3. YP170::GFP reporter $\pm 24-\mathrm{h} 28^{\circ} \mathrm{C}$ HS at 20x and 40x magnification. FigS4: GO term enrichment analyses highlight dynamic stress-induced transcriptomes. FigS5. Oogenesisenriched genes show temporal response to stress. FigS6. Knockdown of YP with ceh-60 RNAi does not restore coelomocyte endocytosis during 24-h $28^{\circ} \mathrm{C} \mathrm{HS}$. FigS7. HSF-1 overexpression provides faster recovery of offspring after $24 \mathrm{~h}$ of $28^{\circ} \mathrm{C} \mathrm{HS}$

Additional file 3: Gene lists. Worksheet with separate tabs for: FigS1 all differentially expressed genes shared between Acute (1-h), Mid (24-h), and Chronic (48-h) $28^{\circ} \mathrm{C} \mathrm{HS}$; FigS2, all differentially expressed genes shared between Chronic (48-h) $28^{\circ} \mathrm{C} \mathrm{HS}$ (this work) and Classical Acute HSR genes $\left(33^{\circ} \mathrm{C} \mathrm{HS}\right.$ for $30 \mathrm{~min}$, from Brunquell et al. [35]); FigS3, GO analysis results including all significantly enriched $\mathrm{GO}$ terms and the upand down-regulated genes from each term for each $28^{\circ} \mathrm{C} \mathrm{HS}$ timepoint (listed by WormBase ID)

\section{Acknowledgements}

The N2, RT130, RT362, and GS1912 strains were provided by the CGC, which is funded by NIH Office of Research Infrastructure Programs (P40 OD010440).
The EQ140 strain was kindly donated by Ao-Lin Hsu (University of Michigan Medical School, Ann Arbor, MI).

\section{Authors' contributions}

RNP performed experiments, analyzed data, and drafted and edited the manuscript. IM collected and analyzed data. RNP, KSKG, and EG designed the experiments, analyzed the data, and edited the manuscript. All authors read and approved the final manuscript.

\section{Funding}

This research was funded by the National Cancer Institute Grant \#R15 CA227573 and the Holzer-Lequear Endowment at the Florida Institute of Technology. Publication of this article was funded in part by the Open Access Subvention Fund and the John H. Evans Library.

\section{Availability of data and materials}

The datasets supporting the conclusions of this article are included within the article and its additional files. Complete sequence reads are available in the Sequence Read Archive (SRA) at NCBI under project number PRJNA705210 [65].

\section{Declarations}

Ethics approval and consent to participate

Not applicable

\section{Consent for publication}

Not applicable

\section{Competing interests}

The authors declare that they have no competing interests.

Received: 15 January 2021 Accepted: 19 March 2021

Published online: 15 April 2021

References

1. Kristensen TN, Ketola T, Kronholm I. Adaptation to environmental stress at different timescales. Ann N Y Acad Sci. 2020;1476(1):5-22. https://doi.org/1 $0.1111 /$ nyas. 13974

2. Greaney JL, Kenney WL, Alexander LM. Sympathetic regulation during thermal stress in human aging and disease. Auton Neurosci. 2016;196:8190. https://doi.org/10.1016/j.autneu.2015.11.002.

3. Sejian V, Bhatta R, Gaughan JB, Dunshea FR, Lacetera N. Review: adaptation of animals to heat stress. Animal. 2018;12:s431-44. https://doi.org/10.1017/ S1751731118001945

4. Bagath M, Krishnan G, Devaraj C, Rashamol VP, Pragna P, Lees AM, Sejian V. The impact of heat stress on the immune system in dairy cattle: a review. Res Vet Sci. 2019;126:94-102. https://doi.org/10.1016/j.rvsc.2019.08.011.

5. Urban MC. Accelerating extinction risk from climate change. Science. 2015; 348(6234):571-3. https://doi.org/10.1126/science.aaa4984.

6. Labbadia J, Morimoto RI. The biology of proteostasis in aging and disease. Annu Rev Biochem. 2015;84(1):435-64. https://doi.org/10.1146/annurevbiochem-060614-033955.

7. Ghosh K, Dill K. Cellular proteomes have broad distributions of protein stability. Biophys J. 2010;99(12):3996-4002. https://doi.org/10.1016/j.bpj.201 0.10 .036 .

8. Vihervaara A, Sistonen L. HSF1 at a glance. J Cell Sci. 2014;127(2):261-6. https://doi.org/10.1242/jcs.132605.

9. Morley JF, Morimoto Rl. Regulation of longevity in Caenorhabditis elegans by heat shock factor and molecular chaperones. Mol Biol Cell. 2004;15(2): 657-64. https://doi.org/10.1091/mbc.E03-07-0532.

10. Hajdu-Cronin YM, Chen WJ, Sternberg PW. The L-type cyclin CYL-1 and the heat-shock-factor HSF-1 are required for heat-shock-induced protein expression in Caenorhabditis elegans. Genetics. 2004;168(4):1937-49. https:// doi.org/10.1534/genetics.104.028423.

11. Hartl FU, Bracher A, Hayer-Hartl M. Molecular chaperones in protein folding and proteostasis. Nature. 2011:324-32. https://doi.org/10.1038/nature10317.

12. Gorenberg EL, Chandra SS. The role of co-chaperones in synaptic proteostasis and neurodegenerative disease. Front Neurosci. 2017;11:1-16. https://doi.org/10.3389/fnins.2017.00248. 
13. Braell WA, Schlossman DM, Schmid SL, Rothman JE. Dissociation of clathrin coats coupled to the hydrolysis of ATP: role of an uncoating ATPase. J Cell Biol. 1984;99(2):735-41. https://doi.org/10.1083/jcb.99.2.734.

14. Jiang R, Baochong G, Prasad K, Greene LE, Eisenberg E. Hsc70 chaperones clathrin and primes it to interact with vesicle membranes. J Biol Chem. 2000;275(12):8439-47. https://doi.org/10.1074/jbc.275.12.8439.

15. Eisenberg E, Greene LE. Multiple roles of auxilin and Hsc70 in clathrinmediated endocytosis. Traffic. 2007;8(6):640-6. https://doi.org/10.1111/j.1 600-0854.2007.00568.x.

16. Chang HC, Hull M, Mellman I. The J-domain protein Rme-8 interacts with $\mathrm{Hsc70}$ to control clathrin-dependent endocytosis in Drosophila. J Cell Biol. 2004;164(7):1055-64. https://doi.org/10.1083/jcb.200311084.

17. Shi A, Sun L, Banerjee R, Tobin M, Zhang Y, Grant BD. Regulation of endosomal clathrin and retromer-mediated endosome to Golgi retrograde transport by the J-domain protein RME-8. EMBO J. 2009;28(21):3290-302. https://doi.org/10.1038/emboj.2009.272.

18. Zhang Y, Grant B, Hirsh D. RME-8, a conserved J-domain protein, is required for endocytosis in Caenorhabditis elegans. Kimble J, editor. Mol Biol Cell. 2001;12(7):2011-21. https://doi.org/10.1091/mbc.12.7.2011

19. Fares H, Greenwald I. Genetic analysis of endocytosis in Caenorhabditis elegans: coelomocyte uptake defective mutants. Genetics. 2001;159:133-45.

20. Anckar J, Sistonen L. Regulation of HSF1 function in the heat stress response: implications in aging and disease. Annu Rev Biochem. 2011;80(1): 1089-115. https://doi.org/10.1146/annurev-biochem-060809-095203.

21. López-Otín C, Blasco MA, Partridge L, Serrano M, Kroemer G. The hallmarks of aging. Cell. 2013;153(6):1194-217. https://doi.org/10.1016/j.cell.2013.05.039.

22. Powers ET, Morimoto RI, Dillin A, Kelly JW, Balch WE. Biological and chemical approaches to diseases of proteostasis deficiency. Annu Rev Biochem. 2009;78(1):959-91. https://doi.org/10.1146/annurev.biochem.0523 08.114844 .

23. Qin G, Johnson C, Zhang Y, Zhang H, Yin J, Miller G, Turingan RG, Guisbert $\mathrm{E}$, Lin Q. Temperature-induced physiological stress and reproductive characteristics of the migratory seahorse Hippocampus erectus during a thermal stress simulation. Biol Open. 2018;7(6). https://doi.org/10.1242/bio. 032888

24. Jastrebski SF, Lamont SJ, Schmidt CJ. Chicken hepatic response to chronic heat stress using integrated transcriptome and metabolome analysis. PLoS One. 2017;12(7):1-15. https://doi.org/10.1371/journal.pone.0181900.

25. Evans TG. Considerations for the use of transcriptomics in identifying the "genes that matter" for environmental adaptation. J Exp Biol. 2015;218(12): 1925-35. https://doi.org/10.1242/jeb.114306.

26. Porcelli D, Butlin RK, Gaston KJ, Joly D, Snook RR. The environmental genomics of metazoan thermal adaptation. Heredity (Edinb). 2015;114(5): 502-14. https://doi.org/10.1038/hdy.2014.119.

27. Russnak RH, Jones D, Candido EP. Cloning and analysis of CDNA sequences coding for two 16 kilodalton heat shock proteins (hsps) in Caenorhabditis elegans: homology with the small hsps of Drosophila. Nucleic Acids Res. 1983;11(10):3187-205. https://doi.org/10.1093/nar/11.10.3187.

28. GuhaThakurta D, Palomar L, Stormo GD, Tedesco P, Johnson TE, Walker DW et al. Identification of a novel cis-regulatory element involved in the heat shock response in Caenorhabditis elegans using microarray gene expression and computational methods. Genome Res. 2002;12(5):701-12. https://doi. org/10.1101/gr.228902

29. Jovic K, Sterken MG, Grilli J, Bevers RPJ, Rodriguez M, Riksen JAG, et al. Temporal dynamics of gene expression in heat-stressed Caenorhabditis elegans. Dupuy D, editor. Plos One. 2017;12:e0189445. https://doi.org/10.13 71/journal.pone.0189445

30. McMullen PD, Aprison EZ, Winter PB, Amaral LAN, Morimoto RI, Ruvinsky I. Macro-level modeling of the response of $C$. elegans reproduction to chronic heat stress. Sporns O, editor. Plos Comput Biol. 2012;8: e1002338. doi: https://doi.org/10.1371/journal.pcbi.1002338

31. Aprison EZ, Ruvinsky I. Balanced trade-offs between alternative strategies shape the response of $C$. elegans reproduction to chronic heat stress. Plos One. 2014;9. https://doi.org/10.1371/journal.pone.0105513.

32. Labbadia J, Morimoto RI. Repression of the heat shock response is a programmed event at the onset of reproduction. Mol Cell. 2015;59(4):63950. https://doi.org/10.1016/j.molcel.2015.06.027

33. Anders $\mathrm{S}$, Huber W. Differential expression analysis for sequence count data. Genome Biol. 2010;11(10):R106. https://doi.org/10.1186/gb-2010-11-10-r106.

34. Benjamini $Y$, Hochberg Y. Controlling the false discovery rate: a practical and powerful approach to multiple testing. J R Stat Soc Ser B. 1995;57:289-300.
35. Brunquell J, Morris S, Lu Y, Cheng F, Westerheide SD. The genome-wide role of HSF-1 in the regulation of gene expression in Caenorhabditis elegans. BMC Genomics. 2016;17(1):559. https://doi.org/10.1186/s12864-01 6-2837-5.

36. Angeles-Albores D, Raymond RY, Chan J, Sternberg PW. Tissue enrichment analysis for C. elegans genomics. BMC Bioinformatics. 2016;17(1):1-10. https://doi.org/10.1186/s12859-016-1229-9.

37. Angeles-Albores D, Lee R, Chan J, Sternberg P. Two new functions in the WormBase Enrichment Suite. microPublication Biol. 2018;2018:2015-7. https://doi.org/10.17912/W25Q2N.

38. Reinke V, Gil IS, Ward S, Kazmer K. Genome-wide germline-enriched and sex-biased expression profiles in Caenorhabditis elegans. Development. 2004;131(2):311-23. https://doi.org/10.1242/dev.00914.

39. Sharrock WJ. Yolk proteins of C. elegans. Dev Biol. 1983;96(1):182-8. https:// doi.org/10.1016/0012-1606(83)90321-4.

40. Blumenthal T, Squire M, Kirtland S, Cane J, Donegan M, Spieth J, Sharrock W. Cloning of a yolk protein gene family from Caenorhabditis elegans. J Mol Biol. 1984;174(1):1-18. https://doi.org/10.1016/0022-2836(84)90361-9.

41. Matyash V, Geier C, Henske A, Mukherjee S, Hirsh D, Thiele C, Grant B, Maxfield FR, Kurzchalia TV. Distribution and transport of cholesterol in Caenorhabditis elegans. Mol Biol Cell. 2001;12(6):1725-36. https://doi.org/1 0.1091/mbc.12.6.1725.

42. Sharrock WJ. Cleavage of two yolk proteins from a precursor in Caenorhabditis elegans. J Mol Biol. 1984;174(3):419-31. https://doi.org/10.1 016/0022-2836(84)90329-2

43. Spieth J, Blumenthal T. The Caenorhabditis elegans vitellogenin gene family includes a gene encoding a distantly related protein. Mol Cell Biol. 1985; 5(10):2495-501. https://doi.org/10.1128/MCB.5.10.2495.

44. Kimble J, Sharrock WJ. Tissue-specific synthesis of yolk proteins in Caenorhabditis elegans. Dev Biol. 1983;96(1):189-96. https://doi.org/10.1016/ 0012-1606(83)90322-6.

45. DePina AS, Iser WB, Park S-SS, Maudsley S, Wilson MA, Wolkow CA. Regulation of Caenorhabditis elegans vitellogenesis by DAF-2/IIS through separable transcriptional and posttranscriptional mechanisms. BMC Physiol. 2011;11(1):11. https://doi.org/10.1186/1472-6793-11-11.

46. Sato M, Sato K, Liou W, Pant S, Harada A, Grant BD. Regulation of endocytic recycling by $C$. elegans Rab35 and its regulator RME-4, a coated-pit protein. EMBO J. 2008:27(8):1183-96. https://doi.org/10.1038/emboj.2008.54.

47. Grant B, Hirsh D. Receptor-mediated endocytosis in the Caenorhabditis elegans oocyte. Kimble J, editor. Mol Biol Cell 1999;10: 4311-4326. doi: https://doi.org/10.1091/mbc.10.12.4311, 12.

48. Hall DH, Winfrey VP, Blaeuer G, Hoffman LH, Furuta T, Rose KL, Hobert O, Greenstein D. Ultrastructural features of the adult hermaphrodite gonad of Caenorhabditis elegans: relations between the germ line and soma. Dev Biol. 1999;212(1):101-23. https://doi.org/10.1006/dbio.1999.9356.

49. Rompay L Van, Borghgraef C, Beets I, Caers J, Temmerman L. New genetic regulators question relevance of abundant yolk protein production in C. Elegans. Sci Rep 2015;5: 1-16. doi:https://doi.org/10.1038/srep16381, 1.

50. Van de Walle P, Geens E, Baggerman G, José Naranjo-Galindo F, Askjaer P, Schoofs $L$, et al. CEH-60/PBX regulates vitellogenesis and cuticle permeability through intestinal interaction with UNC-62/MEIS in Caenorhabditis elegans. Tissenbaum HA, editor. Plos Biol. 2019;17:e3000499. https://doi.org/10.1371/journal.pbio.3000499.

51. Miller TM, Heuser JE. Endocytosis of synaptic vesicle membrane at the frog neuromuscular junction. J Cell Biol. 1984;98(2):685-98. https://doi.org/10.1 083/jcb.98.2.685

52. Maycox PR, Link E, Reetz A, Morris SA, Jahn R. Clathrin-coated vesicles in nervous tissue are involved primarily in synaptic vesicle recycling. J Cell Biol. 1992;118(6):1379-87. https://doi.org/10.1083/jcb.118.6.1379.

53. De Camilli $P$, Takei K. Molecular mechanisms in synaptic vesicle endocytosis and recycling. Neuron. 1996;16(3):481-6. https://doi.org/10.1016/S0896-6273 (00)80068-9.

54. Nonet ML, Grundahl K, Meyer BJ, Rand JB. Synaptic function is impaired but not eliminated in C elegans mutants lacking synaptotagmin. Cell. 1993;73(7): 1291-305. https://doi.org/10.1016/0092-8674(93)90357-V

55. Kraemer BC, Zhang B, Leverenz JB, Thomas JH, Trojanowski JQ, Schellenberg GD. Neurodegeneration and defective neurotransmission in a Caenorhabditis elegans model of tauopathy. Proc Natl Acad Sci. 2003; 100(17):9980-5. https://doi.org/10.1073/pnas.1533448100.

56. Sural S, Lu T-C, Jung SA, Hsu A-L. HSB-1 inhibition and HSF-1 overexpression trigger overlapping transcriptional changes to promote longevity in 
Caenorhabditis elegans. G3 (Bethesda). 2019;9:1679-92. https://doi.org/10.1 534/g3.119.400044.

57. Yu A, Shibata Y, Shah B, Calamini B, Lo DC, Morimoto RI. Protein aggregation can inhibit clathrin-mediated endocytosis by chaperone competition. Proc Natl Acad Sci. 2014;111(15):E1481-90. https://doi.org/10.1 073/pnas.1321811111.

58. Ma J, Grant CE, Plagens RN, Barrett LN, Kim Guisbert KS, Guisbert E. Cellular proteomes drive tissue-specific regulation of the heat shock response. G3 (Bethesda). 2017;7:1011-8. https://doi.org/10.1534/g3.116.038232.

59. Klabonski L, Zha J, Senthilkumar L, Gidalevitz T. A bystander mechanism explains the specific phenotype of a broadly expressed misfolded protein. PLoS Genet. 2016;12(12):1-33. https://doi.org/10.1371/journal.pgen.1006450.

60. Zha J, Ying M, Alexander-Floyd J, Gidalevitz T. HSP-4/BIP expression in secretory cells is regulated by a developmental program and not by the unfolded protein response. Plos Biol. 2019;17(3):1-23. https://doi.org/10.13 71/journal.pbio.3000196.

61. Balklava Z, Pant S, Fares H, Grant BD. Genome-wide analysis identifies a general requirement for polarity proteins in endocytic traffic. Nat Cell Biol. 2007;9(9):1066-73. https://doi.org/10.1038/ncb1627.

62. Snutch TP, Baillie DL. Alterations in the pattern of gene expression following heat shock in the nematode Caenorhabditis elegans. Can J Biochem Cell Biol. 1983;61(6):480-7. https://doi.org/10.1139/083-064.

63. Golden NL, Plagens RN, Kim Guisbert KS, Guisbert E. Standardized methods for measuring induction of the heat shock response in Caenorhabditis elegans. J Vis Exp. 2020;2020(161):1-13. https://doi.org/10.3791/61030.

64. Kamath RS, Ahringer J. Genome-wide RNAi screening in Caenorhabditis elegans. Methods. 2003;30(4):313-21. https://doi.org/10.1016/S1046-2023(03 )00050-1.

65. Plagens RN, Mossiah I, Kim Guisbert KS, Guisbert E. Chronic heat stress transcriptome in C. elegans. NCBI SRA. 2021. https://identifiers.org/ncbi/ insdc.sra:SRP308414.

\section{Publisher's Note}

Springer Nature remains neutral with regard to jurisdictional claims in published maps and institutional affiliations.

Ready to submit your research? Choose BMC and benefit from:

- fast, convenient online submission

- thorough peer review by experienced researchers in your field

- rapid publication on acceptance

- support for research data, including large and complex data types

- gold Open Access which fosters wider collaboration and increased citations

- maximum visibility for your research: over $100 \mathrm{M}$ website views per year

At $\mathrm{BMC}$, research is always in progress.

Learn more biomedcentral.com/submissions 